\title{
Controversies in the treatment of digestive neuroendocrine tumors
}

\author{
Maria Rinzivillo, Francesco Panzuto, Gianfranco Delle Fave \\ Department of Digestive and Liver Disease, Digestive Neuroendocrine Unit, Sant'Andrea Hospital, Sapienza University of Rome, 00189 Rome, Italy.
}

Correspondence to: Prof. Gianfranco Delle Fave, Department of Digestive and Liver Disease, Digestive Neuroendocrine Unit, Sant'Andrea

Hospital, Sapienza University of Rome, Via di Grottarossa 1035-39, 00189 Rome, Italy. E-mail: gianfranco.dellefave@uniroma1.it

\section{A B S T R A C T}

Gastroenteropancreatic neuroendocrine tumors (NETs) have an incidence of 2.39 per 100,000 inhabitants per year, and a prevalence of 35 cases per 100,000 inhabitants; the gap between these rates is due to the relatively long survival time of these tumors, which can be thus considered as chronic oncological diseases. Recently, more therapeutic options have become available, but criteria for defining timing, priority and sequence of different therapeutic options are still debated. This review offers an overview of pancreatic and small bowel NETs, critically underlining the issues that still need to be clarified and some controversial issues on the therapeutic approach for NET patients.

Key words: Neuroendocrine tumors; therapeutic strategy; surgical treatment; medical therapies

\section{INTRODUCTION}

Gastroenteropancreatic neuroendocrine tumors (NETs) are a heterogeneous group of neoplasms derived from the diffuse endocrine system in the gastrointestinal tract and pancreas. The WHO classification classifies these tumors into three principal categories with different malignant behavior: NETs with Ki67 $\leq 2 \%$ (G1 NETs), NETs with Ki67 3-20\% (G2 NETs) and neuroendocrine carcinomas (NECs) with Ki67 > 20\% (NECs G3). ${ }^{[1]}$

In the last few decades, the increasing incidence of these diseases has aroused much interest resulting in improvements in available therapeutic options and new clinical trials. In fact, treatment options for NETs have increased in number and this is definitely an advantage for patients. However, criteria for defining timing, priority and sequence of different therapeutic options are still debated.

The optimal therapeutic sequence should be based on the evaluation of at least three major issues:

\section{(a) Tumor characterization:}

Primary site: pancreatic and small bowel NETs should be considered different diseases in terms of both risk of tumor progression and overall survival;

\begin{tabular}{|l|l|}
\hline \multicolumn{3}{|c|}{ Access this article online } \\
\hline Quick Response Code: & Website: \\
& www.jcmtjournal.com \\
\cline { 2 - 2 } & \\
&
\end{tabular}

Histological diagnosis: conventional immunohistochemistry evaluation and Ki67 assessment are needed to classify the disease according with WHO classification, as well as define tumor grading;

Disease staging: conventional contrast enhanced computed tomography (or magnetic resonance imaging) should be performed together with functional imaging (68 Ga-PET or Octreoscan) to stage the disease according with the ENETS staging system.

\section{(b) Patient's clinical status:}

Performance status;

Presence of symptoms resulting from tumor-related secretion of active substances, in the case of a "functioning tumor";

Prior treatments and comorbidity, which may reduce therapeutic options.

\section{(c) Defining the objectives of care:}

The only curative option is represented by radical surgery;

In most patients, since curative surgery is not feasible, medical treatment is needed to treat advanced

This is an open access article distributed under the terms of the Creative Commons Attribution-NonCommercial-ShareAlike 3.0 License, which allows others to remix, tweak, and build upon the work non-commercially, as long as the author is credited and the new creations are licensed under the identical terms.

For reprints contact: service@oaepublish.com

How to cite this article: Rinzivillo M, Panzuto F, Delle Fave G Controversies in the treatment of digestive neuroendocrine tumors. J Cancer Metasta Treat 2016;2:304-9.

Received: 20-06-2016; Accepted: 26-07-2016. 
unresectable disease;

In "functioning tumors" the symptomatic control is a major therapeutic goal;

In advanced end-stage disease, palliative symptomatic therapies are required to maintain patient's quality of life.

In the present paper, some controversial issues on the therapeutic approach for NET patients will be discussed.

\section{SURGICAL THERAPY}

Small incidental non-functioning pancreatic NETs (pNETs): should they always be removed? Surgical treatment of pNETs must always be planned and adapted to each individual patient considering several variables, including patient characteristics and disease stage. Some studies have recently suggested tumor diameter as the main criterion for surgery with radical intent. ${ }^{[2,3]}$ For pNETs $\leq 2 \mathrm{~cm}$, and in the absence of symptoms and/or suspected metastatic lesions, a conservative wait-and-see approach may be adopted in selected cases, scheduling a clinical and radiological follow-up. ${ }^{[4-7]}$ Pancreatic NETs $\leq$ $2 \mathrm{~cm}$ of diameter have a risk of "malignancy" of about $6 \%$, while 5 -year disease mortality is $0 \%{ }^{[4]}$ In the small and sporadic non-functioning pNETs, the mean overall tumor growth (difference between size at last followup and initial size) was $0.37(+/-1.67) \mathrm{mm}^{[7]}$ Mean growth per month was $0.010(+/-0.051)$ or $0.12 \mathrm{~mm}$ per year corresponding to a growth percentage of $1.5 \%(+/-$ 5.5) from the initial tumor size per year. The incidental diagnosis and the absence of symptoms seem to correlate with a better prognosis in this subgroup of patients. ${ }^{[2]}$ Histological confirmation of tumor neuroendocrine origin by endoscopic ultrasonography with tissue sampling is required before planning a patient's management. The primary tumor localization is an additional major factor to determining the surgical approach. Finally, the patient's comorbidities and willing should always be considered in the surgical management of pNETs.

Despite recent progress, morbidity remains significant, indeed, it is necessary to carefully evaluate the type of surgery, the risks of surgery and the risks related to tumor growth in advance. Based on these considerations, conservative non-surgical management may be proposed in selected patients with small, incidental non-functioning pNETs.

\section{Pancreatic NETs with liver metastases: should the primary tumor be resected?}

The presence of metastases is the main factor associated with mortality in pNET patients. Surgical options for patients, including those with metastatic disease, include different procedures such as curative liver and pancreatic resection, primary resection, local ablative techniques, and liver transplantation. In these cases, patient selection must be meticulous and consider several prerequisites including: (a) the presence of well - differentiated lesions; (b) the absence of extra - abdominal disease; and (c) the absence of diffuse peritoneal carcinomatosis. ${ }^{[8]}$

In the literature, clinical studies suggest that there is a possible benefit in terms of survival when performing surgical removal of primitive pNETs if metastases are present. ${ }^{[9]}$ However, in the retrospective studies that evaluated the role of surgery in pNETs with unresectable liver metastases, there is a selection bias for patients related to the localization of primary tumors and the type of surgical approach, the patient status in terms of comorbidity, age and performance status. ${ }^{[9]}$ In the Partelli et $a l .{ }^{[10]}$ paper, the 5-year overall survival (OS) after surgical resection was $76 \%$ with an increase to $88 \%$ after curative resection. Although palliative surgery was associated with an improved outcome, surgical management should be reserved in highly selected patients due to the high risk of peri/postoperative complications.

\section{Small intestinal NETs (SI-NETs) with liver metastases: should the primary tumor be resected?}

Surgical treatment of SI-NETs is affected by disease clinical presentation. For SI-NETs diagnosed as stage I-III, the choice of therapy is always surgical bowel resection with lymphadenectomy. ${ }^{[11-13]}$ Curative resection of the primary tumor and regional lymph node metastasis site improves long-term outcome, with a 100\% 5-10 year survival for patients with stage I and II tumors and more than $80 \%$ for patients with stage III jejuno-ileal NETs. ${ }^{[14]}$ In the presence of synchronous liver lesions, surgical treatment is still highly debated. A recent systematic review ${ }^{[15]}$ analyzed the studies in the literature on the surgical resection of the primary tumor in patients with SI-NETs and distant metastases. Although it was not possible to conduct a meta-analysis of these works, the conclusions suggest improved survival after surgical removal of the primary tumor in patients with metastatic unresectable disease and a reduction in local complications (bleeding, perforation, and occlusion). In association with the intestinal resection, cholecystectomy should be performed in order to prevent gallstones due to long-term treatment with somatostatin analogue. ${ }^{[16]}$

\section{MEDICAL THERAPY}

Being characterized by a relatively long OS, multiple sequential therapies are adopted in digestive NETs although the best sequence for these patients is not well defined.

\section{Somatostatin analogs (SSAs): are they indicated for all NET patients?}

SSAs clearly represent the first-line treatment for patients with functioning NETs. As far as non-functioning tumors are concerned, SSAs can control tumor proliferation, as shown by two randomized clinical trials. The PROMID 
study ${ }^{[17]}$ described, in 42 metastatic patients treated by octreotide long-acting repeatable (LAR) $30 \mathrm{mg}$, a median progression-free survival (PFS) of 14.3 months vs. 6 months of the 43 cases enrolled in the placebo group. The more recent CLARINET trial ${ }^{[18]}$ showed, in 101 patients with digestive NET using lanreotide $120 \mathrm{mg}$, a median PFS not reached $v s .18$ months of the 103 included in the placebo group. Both studies highlight the increased antiproliferative activity of these drugs in patients with low Ki67 (G1 NETs or G2 NETs with Ki67 < 10\%), stable slow-growing disease, and high somatostatin receptor expression as assessed by functional imaging. Alternative medical treatments should be considered if these criteria are not satisfied.

\section{Peptide receptors radionuclide therapy (PRRT): is there a place as a first-line approach?}

PRRT acts with the same molecular mechanism as SSAs, but the somatostatin analog is radiolabeled with Y90 or Lu177, performing an "in loco" radiotherapy. This welltolerated treatment is able to inhibit tumor growth in up to $50-70 \%$ of digestive NETs. ${ }^{[19-21]}$

Results from the first Phase III, multicenter randomized clinical trial (RCT) comparing Lutathera ${ }^{\circledR} v$ s. Octreotide in patients with inoperable, progressive, somatostatin receptor-positive G1-G2 small intestinal NETs (NETTER-1 trial) have been recently presented at the last ECC (Vienna, September 2015) (www.clinicaltrials. gov NCT01578239).. ${ }^{[21]}$ They showed that, in 230 patients enrolled, the median PFS was not reached in the PRRTtreated group vs. 8.4 months obtained by SSA [hazard ratio (HR): $0.21, P<0.0001]$. This data supports the benefit of this therapy in metastatic small intestinal NETs, and hopefully will help achieve official registration of this drug. ${ }^{[21]}$

All international guidelines (ENETS, NANETS, ESMO, and NCCN) consider PRRT as a valid option in patients with advanced NETs; however, there are no solid data supporting where PRRT should be placed in the therapeutic sequence. A recent multicenter Italian study on the compassionate use of everolimus in advanced NETs highlighted the increasing risk of severe toxicity in patients who had been previously treated with PRRT or chemotherapy, thus suggesting the early use of everolimus in patients with advanced NETs. ${ }^{[22]}$ Furthermore, Bajetta et $a l .{ }^{[23]}$ treated patients with everolimus in combination with octreotide LAR as first line approach in advanced NETs and showed that in this setting, this combination treatment is very effective with disease control being reached in $92 \%$ of patients. This therapy also has an excellent safety profile, with only one single grade 4 adverse event in the population of 50 patients enrolled. ${ }^{[23]}$ Conversely in a relatively small series of NET patients treated with everolimus after previous failure of PRRT, Kamp et al. ${ }^{[24]}$ reported an overall safety profile similar to that presented in the randomized clinical trials. However in this trial, severe kidney toxicity was observed in $4.2 \%$ of patients, a toxicity not reported in the regulatory trials, where no patients pre-treated with PRRT had been enrolled. To date, no conclusive data on the optimal therapeutic sequence involving PRRT is available and caution should be used when considering everolimus therapy in patients who have previously received PRRT.

\section{Targeted therapies: everolimus or sunitinib first?}

Another relevant option for digestive NETs is targeted therapy. Recent trials have demonstrated the activity of the mTOR inhibitor everolimus (RAD001, Afinitor ${ }^{\circledR}$, Novartis Oncology) against tumor growth. In the RADIANT-3 trial, ${ }^{[25]}$ a phase III placebo-controlled study enrolling advanced pNETs, everolimus provided a significant prolongation in median PFS $v s$. placebo (11 and 4.6 months; 207 and 203 patients, respectively). The results of this trial led to approval by the U.S. Food and Drug Administration (FDA) and the European Medicines Agency (EMA) for the treatment of locally advanced, metastatic or unresectable pNETs. ${ }^{[2]}$ Its activity has also been reported in progressive, well-differentiated, nonfunctioning lung and non-pancreatic digestive NETs, based on the findings of the RADIANT-4 RCT. ${ }^{[26]}$ This study showed a significant benefit with everolimus in these patients, with median PFS being 11 months in the treatment arm $(n=205)$ vs. 3.9 months in the placebo group $(n=97)$ (HR: $0.64, P=0.037) .{ }^{[26]}$ The most common adverse events reported in the phase III RCTs (Radiant 3-4) (> 30\%) were stomatitis $(62 \%, 64 \%)$, rash $(37 \%, 49 \%)$, fatigue $(31 \%, 31 \%)$ and diarrhea $(27 \%, 34 \%)$, while grade $3 / 4$ treatment-related adverse events were stomatitis $(7 \%, 7 \%)$, anemia $(1 \%, 6 \%)$, and hyperglycemia $(5 \%, 5 \%)$. Overall, grade $3-4$ toxicity was reported in approximately $5-8 \%$ of patients. This data suggests caution when using everolimus in patients with diabetes, in whom an optimal glucose control is mandatory before beginning the treatment.

Sunitinib (Sutent ${ }^{\mathbb{}}$, Pfizer) is another targeted therapy, effective for the treatment of advanced pNETs. It is an antiangiogenic, pan-receptor tyrosine kinase inhibitor, acting against multiple targets including VEGFR, PDGFR, c-KIT, Flt-3 and RET. In the phase III RCT published in 2011, it prolonged PFS to 10.2 months vs. 5.4 with placebo. ${ }^{[27]}$ The most common adverse events reported in the sunitinib trial were diarrhea $(59 \%)$, nausea, fatigue, vomiting (35\%) and fatigue (32\%), while the most frequent grade $3 / 4$ treatment-related included neutropenia $(12 \%)$, hypertension $(10 \%)$, and palmarplantar erythrodysesthesia (6\%). Notably, because patients with severe cardiac comorbidities had not been enrolled in this study, caution should be exercised when using sunitinib in patients with a significant cardiac history (e.g., arrhythmia, coronary artery disease, cardiomyopathy, uncontrolled hypertension). Grade 3-4 toxicity was present in up to $12 \%$ of patients. 
The choice of which targeted agent should be used first still remains a challenge for physicians dealing with advanced pNETs. No comparative study of everolimus versus sunitinib in this setting is available yet. Thus, since phase III trials have demonstrated a similar efficacy in terms of PFS, the choice is mainly based on the evaluation of other elements, including the toxicity profile, patients' comorbidity, and physician's expertise with these drugs. An additional point of interest that should be considered, besides the physician's personal clinical experience when managing these drugs, is the larger population of NET patients treated with everolimus in comparison with sunitinib reported in the literature. In fact, more than 600 advanced NET patients have been treated in the RADIANT trials, ${ }^{[25,26,28]}$ in comparison with the 86 patients included in the sunitinib trial. ${ }^{[27]}$

\section{G3 NECs: is platinum-based chemotherapy always required?}

According with the WHO 2010 classification, ${ }^{[1]}$ the group of G3 NECs were identified with a proliferation index (Ki67) $>20 \%$ (or > 20 mitotic count per $10 \mathrm{HPF}$ ). International guidelines ${ }^{[29]}$ suggest the use of platinumbased systemic chemotherapy in G3 NEC patients due to the rapidly metastatic behavior of these tumors, and the extremely poor prognosis in comparison with other NETs with lower proliferative activity (G1 and G2). However, this category constitutes a heterogeneous group of diseases, including both well-differentiated and poorly differentiated tumors based on morphological features, with different implications in terms of patients' prognosis and therapeutic approach. ${ }^{[30,31]}$ Overall, median PFS reported with platinum-based first-line approach ranges from 4 to 9 months. ${ }^{[31]}$ However, this data mostly derives from non-randomized trials, with small series of patients evaluated by a retrospective design approach, and usually enrolling a heterogeneous series of patients in terms of therapeutic schedules and biological features of the tumor (primary site, staging, Ki67 index).

Data reported by the Nordic group study ${ }^{[31]}$ proposes to consider G3 NECs with Ki67 $<55 \%$, as a different entity that exhibits less aggressive behavior and responds well to platinum-based chemotherapy, in comparison with other G3 NECs. This specific subgroup of patients might be considered as a separate disease in which therapeutic approaches other than platinum-based should be tested. Indeed, the role of everolimus in G3 NECs is under investigation in phase II trials in several different clinical settings (MAVERIC- EudraCT: 2014-003951-72, www. clinicaltrials.gov, NCT0211380, www.clinicaltrials.gov NCT02248012).

Further prospective studies are required before considering therapeutic options based on targeted agents as the standard treatments in G3 NECs.
Locoregional therapies: is there an impact on patients' survival?

In some cases (especially with a functional syndrome) when a complete resection is not possible, debulking surgery can be performed to improve prognosis and quality of life. This approach can be based on the combination of surgery on primary and secondary tumors and locoregional treatments (i.e., trans-arterial liver embolization, TAE; trans-arterial chemoembolization, TACE; radiofrequency ablation). Embolization is contraindicated in patients with portal vein thrombosis, liver insufficiency, biliary obstruction or prior Whipple procedure. The presence of portal vein occlusion or ascites hepatic tumor burden $>75 \%$ of the total liver are considered relative contraindications. ${ }^{[32]}$ In a retrospective study in patients with pNETs, chemoembolization showed better results when compared with bland embolization (response: $50 \%$ vs. $25 \%$, respectively). ${ }^{[33]}$ However, no clear difference between TAE and TACE in terms of clinical outcome has been reported so far.

Another experimental approach to metastatic disease is selective internal radiation therapy (SIRT), based on the intra-arterial deliver of Yttrium-90 microspheres to the lesions. Although results seem appealing, they are from retrospective series, and a recent study comparing this technique to TAE and TACE over a 10 -year period did not show any advantages of SIRT in terms of time to disease progression. ${ }^{[34]}$

The wide range in response rates and survival duration in various studies in terms of patient population and tumor profile, the extent of liver involvement, and the presence of extra-hepatic metastases is reflection of the heterogeneous tumor biology of this disease. Gupta et al. ${ }^{[33]}$ found that patients treated with liver embolization with carcinoid tumors had a higher response rate $(66.7 \%$ vs. $35 \% ; P<0.0001)$, longer time to progression (TTP) (22.7 months vs. 16.1 months, $P$ $<0.046$ ), and better OS (33.8 months vs. 23.2 months; $P<0.012)$ compared to patients with pNETs. Roche et $a l .{ }^{[35]}$ found non-pancreatic NETs $(P<0.006)$, absence of extra-hepatic lesions $(P<0.03)$, unresected primary $(P<0.012)$ and TACE as first-line $(P<0.028)$ were significant for complete response to liver emoblization, and less hepatic involvement $(<30 \%)$ significantly improved morphological response $(P<0.016)$. There is no conclusive evidence in the literature that the locoregional therapies improve survival rate.

\section{CONCLUSION}

Despite recent advances in the knowledge of digestive NETs, there are still many controversial aspects about the management of these patients. There is a dire need for further multicenter studies designed to clarify gray areas such as the sequence of medical therapies in patients with advanced disease, the opportunity for a conservative 
follow-up in small incidental tumors of the pancreas, the optimal approach to NEC G3 tumors with well differentiated morphology, liver ablative therapies, and surgery in the context of metastatic disease.

\section{Financial support and sponsorship}

Nil.

\section{Conflicts of interest}

There are no conflicts of interest.

\section{REFERENCES}

1. Bosman FT, Carneiro F, Hruban RH, Theise ND. World Health Organization Classification of Tumours. Pathology and Genetics. Tumors of the Digestive System. Lyon: IARC Press; 2010.

2. Bettini R, Partelli S, Boninsegna L, Capelli P, Crippa S, Pederzoli $\mathrm{P}$, Scarpa A, Falconi M. Tumor size correlates with malignancy in nonfunctioning pancreatic endocrine tumor. Surgery 2011;150:75-82.

3. Lee LC, Grant CS, Salomao DR, Fletcher JG, Takahashi N, Fidler JL, Levy MJ, Huebner M. Small, nonfunctioning, asymptomatic pancreatic neuroendocrine tumors (PNETs): role for nonoperative management. Surgery 2012;152:965-74.

4. Hill JS, McPhee JT, McDade TP, Zhou Z, Sullivan ME, Whalen GF, Tseng JF. Pancreatic neuroendocrine tumors: the impact of surgical resection on survival. Cancer 2009;115:741-51.

5. Falconi M, Zerbi A, Crippa S, Balzano G, Boninsegna L, Capitanio V, Bassi C, Di Carlo V, Pederzoli P. Parenchyma-preserving resections for small nonfunctioning pancreatic endocrine tumors. Ann Surg Oncol 2010;17:1621-7.

6. Crippa S, Zerbi A, Boninsegna L, Capitanio V, Partelli S, Balzano G, Pederzoli P, Di Carlo V, Falconi M. Surgical management of insulinomas: short- and long-termoutcomes after enucleations and pancreatic resections. Arch Surg 2012;147:261-6.

7. Gaujoux S, Partelli S, Maire F, D’Onofrio M, Larroque B, Tamburrino D, Sauvanet A, Falconi M, Ruszniewski P. Observational study of natural history of small sporadic non functioning pancreatic neuroendocrine tumors. J Clin Endocrinol Metab 2013;98:4784-9.

8. Steinmüller T, Kianmanesh R, Falconi M, Scarpa A, Taal B, Kwekkeboom DJ, Lopes JM, Perren A, Nikou G, Yao J, Delle Fave GF, O’Toole D; Frascati Consensus Conference participants. Consensus guidelines for the management of patients with liver metastases from digestive (neuro)endocrine tumors: foregut, midgut, hindgut, and unknown primary. Neuroendocrinology 2008;87:47-62.

9. Capurso G, Bettini R, Rinzivillo M, Boninsegna L, Delle Fave G, Falconi M. Role of resection of the primary pancreatic neuroendocrine tumour only in patients with unresectable metastatic liver disease: a systematic review. Neuroendocrinology 2011;93:223-9.

10. Partelli S, Inama M, Rinke A, Begum N, Valente R, Fendrich V, Tamburrino D, Keck T, Caplin ME, Bartsch D, Thirlwell C, Fusai G, Falconi M. Long-term outcomes of surgical management of pancreatic neuroendocrine tumors with synchronous liver metastases. Neuroendocrinology 2015;102:68-76.

11. Ahlman H, Wängberg B, Jansson S, Friman S, Olausson M, Tylén U, Nilsson O. Interventional treatment of gastrointestinal neuroendocrine tumours. Digestion 2000;62 Suppl 1:59-68.

12. Makridis C, Oberg K, Juhlin C, Rastad J, Johansson H, Lörelius LE, Akerström G. Surgical treatment of mid-gut carcinoid tumors. World J Surg 1990;14: 377-83; discussion 384-5.

13. Sutton R, Doran HE, Williams EM, Vora J, Vinjamuri S, Evans J, Campbell F, Raraty MG, Ghaneh P, Hartley M, Poston GJ, Neoptolemos JP. Surgery for midgut carcinoid. Endocr Relat Cancer 2003;10:469-81.
14. Jann H, Roll S, Couvelard A, Hentic O, Pavel M, Müller-Nordhorn J, Koch M, Röcken C, Rindi G, Ruszniewski P, Wiedenmann B, Pape UF. Neuroendocrine tumors of midgut and hindgut origin: tumor-node-metastasis classification determines clinical outcome. Cancer 2011;117:3332-41.

15. Capurso G, Rinzivillo M, Bettini R, Boninsegna L, Fave GD, Falconi M. Systematic review of resection of primary midgut carcinoid tumour in patients with unresectable liver metastases. $\mathrm{Br}$ J Surg 2012;99:1480-6.

16. Norlen O, Hessman O, Stålberg P, Akerström G, Hellman P. Prophylactic cholecystectomy in midgut carcinoid patients. World J Surg 2010;34:1361-7.

17. Rinke A, Müller HH, Schade-Brittinger C, Klose KJ, Barth P, Wied M, Mayer C, Aminossadati B, Pape UF, Bläker M, Harder J, Arnold C, Gress T, Arnold R; PROMID Study Group. Placebocontrolled, double- blind, prospective, randomized study on the effect of octreotide LAR in the control of tumor growth in patients with metastatic neuroendocrine midgut tumors: a report from the PROMID Study Group. J Clin Oncol 2009;27:4656-63.

18. Caplin ME, Pavel M, Ćwikła JB, Phan AT, Raderer M, Sedláčková E, Cadiot G, Wolin EM, Capdevila J, Wall L, Rindi G, Langley A, Martinez S, Blumberg J, Ruszniewski P; CLARINET Investigators. Lanreotide in metastaticenteropancreatic neuroendocrine tumors. $N$ Engl J Med 2014;371:224-33.

19. Bodei L, Cremonesi M, Zoboli S, Grana C, Bartolomei M, Rocca P, Caracciolo M, Mäcke HR, Chinol M, Paganelli G. Receptormediated radionuclide therapy with 90Y-DOTATOC in association with amino acid infusion: a phase I study. Eur J Nucl Med Mol Imaging 2003;30:207-16.

20. Kwekkeboom DJ, de Herder WW, Kam BL, van Eijck CH, van Essen M, Kooij PP, Feelders RA, van Aken MO, Krenning EP. Treatment with the radiolabeled somatostatin analog $[177 \mathrm{Lu}-$ DOTA 0,Tyr3]octreotate: toxicity, efficacy, and survival. $J$ Clin Oncol 2008;26:2124-30.

21. Strosberg J, Wolin E, Chasen B, Kulke M, Bushnell D, Caplin M, Baum RP, Mittra E, Hobday T, Hendifar A, Oberg K, Lopera Sierra M, Ruszniewski P, Kwekkeboom D; on behalf of the NETTER-1 study group. 177-Lu-Dotatate significantly improves progressionfree survival in patients with midgut neuroendocrine tumours: results of the phase III NETTER-1 trial. Late Breaking Abstract (6LBA) a the 2015 European Cancer Congress (ECC), Vienna, Austria.

22. Panzuto F, Rinzivillo M, Fazio N, de Braud F, Luppi G, Zatelli MC, Lugli F, Tomassetti P, Riccardi F, Nuzzo C, Brizzi MP, Faggiano A, Zaniboni A, Nobili E, Pastorelli D, Cascinu S, Merlano M, Chiara S, Antonuzzo L, Funaioli C, Spada F, Pusceddu S, Fontana A, Ambrosio MR, Cassano A, Campana D, Cartenì G, Appetecchia M, Berruti A, Colao A, Falconi M, Delle Fave G. Real-world study of everolimus in advanced progressive neuroendocrine tumors. Oncologist 2014;19:966-74.

23. Bajetta E, Catena L, Fazio N, Pusceddu S, Biondani P, Blanco G, Ricci S, Aieta M, Pucci F, Valente M, Bianco N, Mauri CM, Spada F. Everolimus in combination with octreotidelong-actingrepeatable in a first-line setting for patients with neuroendocrine tumors: an ITMO group study. Cancer 2014:120:2457-63.

24. Kamp K, Gumz B, Feelders RA, Kwekkeboom DJ, Kaltsas G, Costa FP, de Herder WW. Safety and efficacy of everolimus in gastrointestinal and pancreatic neuroendocrine tumorsafter (177) Lu-octreotate. Endocr Relat Cancer 2013;20:825-31.

25. Yao JC, Shah MH, Ito T, Bohas CL, Wolin EM, Van Cutsem E, Hobday TJ, Okusaka T, Capdevila J, de Vries EG, Tomassetti P, Pavel ME, Hoosen S, Haas T, Lincy J, Lebwohl D, Öberg K. Everolimus for advanced pancreatic neuroendocrine tumors. $N$ Engl J Med 2011;364:514-23.

26. Yao JC, Fazio N, Singh S, Buzzoni R, Carnaghi C, Wolin E, Tomasek J, Raderer M, Lahner H, Voi M, Pacaud LB, Rouyrre N, Sachs C, Valle JW, Delle Fave G, Van Cutsem E, Tesselaar M, 
Shimada Y, Oh DY, Strosberg J, Kulke MH, Pavel ME; RAD001 in Advanced Neuroendocrine Tumours, Fourth Trial (RADIANT-4) Study Group. Everolimus for the treatment of advanced, nonfunctional neuroendocrine tumours of the lung or gastrointestinal tract (RADIANT-4): a randomised, placebo-controlled, phase 3 study. Lancet 2016;387:968-77.

27. Raymond E, Dahan L, Raoul JL, Bang YJ, Borbath I, LombardBohas C, Valle J, Metrakos P, Smith D, Vinik A, Chen JS, Hörsch D, Hammel P, Wiedenmann B, Van Cutsem E, Patyna S, Lu DR, Blanckmeister C, Chao R, Ruszniewski P. Sunitinib malate for the treatment of pancreatic neuroendocrine tumors. $N$ Engl J Med 2011;364:501-13.

28. Pavel ME, Hainsworth JD, Baudin E, Peeters M, Hörsch D, Winkler RE, Klimovsky J, Lebwohl D, Jehl V, Wolin EM, Oberg K, Van Cutsem E, Yao JC; RADIANT-2 Study Group. Everolimus plus octreotide long-acting repeatable for the treatment of advanced neuroendocrine tumours associated with carcinoid syndrome (RADIANT-2): a randomised, placebo-controlled, phase 3 study. Lancet 2011;378:2005-12.

29. Eriksson B, Annibale B, Bajetta E, Mitry E, Pavel M, Platania M, Salazar R, Plöckinger U; Mallorca Consensus Conference participants; European Neuroendocrine Tumor Society. ENETS consensus guidelines for the standards of care in neuroendocrine tumors: chemotherapy in patients with neuroendocrine tumors. Neuroendocrinology 2009;90:214-9.

30. Vélayoudom-Céphise FL, Duvillard P, Foucan L, Hadoux J, Chougnet CN, Leboulleux S, Malka D, Guigay J, Goere D, Debaere
T, Caramella C, Schlumberger M, Planchard D, Elias D, Ducreux M, Scoazec JY, Baudin E. Are G3 ENETS neuroendocrine neoplasms heterogeneous? Endocr Relat Cancer 2013;20:649-57.

31. Sorbye H, Welin S, Langer SW, Vestermark LW, Holt N, Osterlund P, Dueland S, Hofsli E, Guren MG, Ohrling K, Birkemeyer E, Thiis-Evensen E, Biagini M, Gronbaek H, Soveri LM, Olsen IH, Federspiel B, Assmus J, Janson ET, Knigge U. Predictive and prognostic factors for treatment and survival in 305 patients with advanced gastrointestinal poorly differentiated neuroendocrine carcinoma: the NORDIC NEC study. Ann Oncol 2013;24:152-60.

32. Dominguez S, Denys A, Madeira I, Hammel P, Vilgrain V, Menu Y, Bernades P, Ruszniewski P. Hepatic arterial chemoembolization with streptozotocin in patients with metastatic digestive endocrine tumours. Eur J Gastroenterol Hepatol 2000;12:151-7.

33. Gupta S, Johnson MM, Murthy R, Ahrar K, Wallace MJ, Madoff DC, McRae SE, Hicks ME, Rao S, Vauthey JN, Ajani JA, Yao JC. Hepatic arterial embolization and chemoembolization for the treatment of patients with metastatic neuroendocrine tumors: variables affecting response rates and survival. Cancer 2005; 104:1590-602.

34. Yang TX, Chua TC, Morris DL. Radioembolization and chemoembolization for unresectable neuroendocrine liver metastases - a systematic review. Surg Oncol 2012;21:299-308.

35. Roche A, Girish BV, de Baere T, Ducreux M, Elias D, Laplanche A, Boige V, Schlumberger M, Ruffle P, Baudin E. Prognostic factors for chemoembolization in liver metastasis from endocrine tumors. Hepatogastroenterology 2004;51:1751-6. 